\title{
DIREITOS HUMANOS E EDUCAÇÃO: SURDOS NA ESCOLA
}

\author{
HUMAN RIGHTS AND EDUCATION: THE DEAF IN THE SCHOOL \\ DERECHOS HUMANOS Y EDUCACIÓN: SORDOS EN LA ESCUELA
}

\author{
Marcus Vinicius Alves Galvão * \\ Christiane de Holanda Camilo **
}

\section{Resumo}

A educação do surdo é um tema recorrente que nos últimos anos tem sido abordado, tanto de maneira isolada, quanto de forma interdisciplinar, por áreas diversas. Este artigo objetiva investigar, a partir da fala de profissionais que lidam diretamente com o surdo no ambiente escolar, como está ocorrendo sua inclusão, tendo em vista os Direitos Humanos. Trata-se de uma pesquisa transversal, qualitativa, com aplicação de entrevistas semi-estruturadas a gestoras e intérprete de Libras de duas escolas públicas do município de Goiânia. Observou-se que esforços têm sido feitos para a inclusão dos surdos, mas esses ainda relatam dificuldades no acolhimento, que é falho no que diz respeito à dignidade humana. Os resultados desta pesquisa mostram que a inclusão do educando surdo está acontecendo apenas em nível social e não em nível cognitivo, o que não deveria acontecer, pois incluir é proporcionar condições para o acesso, a permanência e a saída do educando da escola.

Palavras-chave: Direitos Humanos, Inclusão, Surdo.

\section{Introdução}

Inclusão escolar significa falar do educando, neste caso, do surdo, que vivencia e participar daquilo que o sistema educacional oferece, sendo fundamental para sua compreensão a definição de termos como: "escola", palavra derivada do grego scholē ( $\sigma \chi 0 \lambda \eta \dot{\eta})$, para a qual, de acordo com a etimologia, há diferentes significados, entre eles: intervalo de trabalho, lazer para a aprendizagem, conversa, debate, palestra, local de encontro para professores e alunos e lugar de instrução. O termo “incluir”, por sua vez, origina-se do latim

\footnotetext{
* Mestrando em Ciências da Saúde da Faculdade de Medicina (UFG). Especialista em Direitos Humanos da Criança e do Adolescente. Graduação em Musicoterapia (UFG). Integrante do Grupo de Estudos e pesquisa em Musicoterapia do CNPq. Tradutor/Intérprete de Língua Brasileira de Sinais. E-mail: markusvag@gmail.com

** Doutoranda em Sociologia (UFG), Mestre em Direitos Humanos (UFG). Pesquisadora do Núcleo Interdisciplinar de Estudos e Pesquisas em Direitos Humanos (NDH / UFG), do Núcleo de Estudos sobre Criminalidade e Violência (NECRIVI/UFG), membro do Grupo de Pesquisa Memória, Cidadania e Direitos Humanos. Professora da Faculdade de Direito da Universidade Federal do Tocantins (UFT) e da Universidade Estadual do Tocantins (UET). E-mail: christianedeholanda@gmail.com
} 
(includere), e significa, no sentido etimológico, "conter em", "compreender", "fazer parte de", ou "participar de". Ambas as definições são importantes neste trabalho, pois são, respectivamente, o lócus e a ação do que será discutido (CUNHA, 2000).

Tal interesse se justifica a fim de ampliar as discussões a respeito do acolhimento e da permanência dos surdos no ambiente escolar, visto que esse é um direito legal, além de contribuir, com esta discussão, para a área da Educação e dos Direitos Humanos, tendo como pressuposto a interdisciplinaridade.

Estima-se que 15 milhões de brasileiros apresentem algum tipo de deficiência, entretanto, em 2009, apenas 639.718 pessoas com deficiência estavam matriculadas na escola, mostrando que uma questão ainda longe de ser solucionada é a inclusão desses alunos. Segundo pesquisa do IBGE, de 2010, 36,7\% das escolas públicas e 26,4\% das escolas particulares incluem alunos com deficiência.

A partir dessa preocupação e desse quantitativo, esta pesquisa de cunho qualitativo se propõe, com o uso de entrevistas com profissionais que lidam diretamente com o sujeito surdo, apontar como acontece a inclusão na atualidade, em escolas inclusivas de Goiânia.

\section{Direitos Humanos, direito da criança e a inclusão}

O processo histórico da construção dos Direitos Humanos perpassa as revoluções burguesas. Esses processos históricos fundam a construção dos direitos civis e políticos, cunhados pelas ideias liberais, nascidas da maturidade e do desejo da burguesia de tomar para si privilégios antes restritos ao clero e à aristocracia. Sobre essa trajetória de lutas e conquistas, Fuziwara (2013, p. 530) afirma ser essa uma referência histórica, a partir da qual é possível:

[...] compreendermos a busca da liberdade individual e da ruptura com a dependência interpessoal, traço marcante da sociedade feudal, que ainda mantinha resquícios naquele capitalismo nascente. Nesse sentido, o contrato entre "pessoas livres" seria o elemento-chave para o avanço da sociedade, que passaria a ter novos proprietários (por aquisição, e não apenas por herança). Contudo, para a elaboração de regras nessa nova forma de relação social, os burgueses liberais também precisavam consolidar direitos políticos — de votar e de ser votado - , para romper com o comando da nobreza e do clero. Era preciso construir uma nova classe política e também era necessária a defesa da laicidade. 
Nesse sentido, Trindade (2003) afirma que a Declaração dos Direitos Humanos de 1948 foi resultado de uma correlação mundial de forças, pois sem a pressão dos países do bloco soviético e sem a ascensão operária, em quase todo o mundo, seria inimaginável a inclusão dos direitos econômicos, sociais e culturais naquele documento. Quanto aos direitos fundamentais da criança e do adolescente, é possível visualizá-los no documento a partir do art. $25^{\circ}, \S 2^{\circ}$, que afirma: "A maternidade e a infância têm direito a cuidados e assistência especiais. Todas as crianças nascidas dentro ou fora do matrimônio gozarão da mesma proteção" (UNESCO, 1948).

De acordo com Paula e Paula (2015) é imprescindível buscar uma definição de Direitos Humanos, para que possamos situar histórica e socialmente a emergência de políticas de valorização destes direitos e a criação de instrumentos efetivos para que os direitos de proteção da criança e adolescente sejam respeitados. De acordo com Paula e Paula os Direitos Humanos podem ser compreendidos como:

[...] os direitos fundamentais da pessoa humana, pelo progressivo reconhecimento pelas nações e instrumentos internacionais, da inerente dignidade de todo indivíduo, independentemente de raça, sexo, idade ou nacionalidade.Os Direitos Humanos podem ser apresentados sob dois aspectos: por um lado, constituem restrições ao poder do Estado, e por outro, condições mínimas para uma existência digna, asseguradas a todo indivíduo (2015, p.1).

Os Direitos Humanos, contudo, muitas vezes se apresentam de forma diversa e fragmentada. Camilo (2014, p. 105) destaca a importância de se considerar os Direitos Humanos em suas dimensões de universalidade, irrenunciabilidade, indivisibilidade, interdependência, interrelacionaridade, imprescritibilidade, inalienabilidade, historicidade, efetividade, aplicabilidade imediata, e vedação ao retrocesso. Para além dessas características a autora apresenta uma construção didática sobre o surgimento dos Direitos Humanos ao longo da história, classificando-os cronologicamente, em gerações. De acordo com Camilo,

[...] os direitos de primeira geração seriam os direitos civis e políticos [...], localizados no século XIX, aqueles relacionados à vida, à propriedade, à liberdade, à igualdade (formal) e participação política [...], os direitos de segunda geração ou dimensão, datados do final do século XX, seriam os direitos sociais, econômicos e culturais como trabalho, moradia, educação, saúde e lazer que relacionados ao Estado lhe cobram prestações positivas; os de terceira geração ou dimensão [...], desenvolvidos ao longo do século XX 
concomitantemente com a universalização dos Direitos Humanos, são os direitos à autodeterminação dos povos, à paz, à qualidade de vida, ao meio ambiente, à comunicação e à conservação do patrimônio histórico cultural humano, [...] os direitos de quarta geração [...] são os direitos do final do século XX e início do século XXI, relacionados à genética, à bioética e seus desdobramentos como clonagem, mudança de sexo, eutanásia, etc.; e por fim, os direitos de quinta geração ou dimensão seriam aqueles adstritos a temáticas como os direitos virtuais em razão da internet, e assim as questões sobre a imagem, honra entre outros (CAMILO, 2014, p. 105)

Esse tipo de classificação, segundo Camilo (2014), considera que as gerações se sucedem e que cada grupo ocupa diferentes dimensões, em termos de direitos. Os Direitos Humanos, como resultado das conquistas históricas da humanidade, não se exauriram. Não foram totalmente realizados, mas em cada nação, povo, etnia ou indivíduo, encontram-se em diferentes etapas de implementação. Na atualidade, os Direitos Humanos "compõem um rol de direitos e a uma cultura de direitos em expansão que não cabe retrocesso, justamente por tratar-se de direitos cujo exercício é a base fundamental da existência e convivência no planeta" (CAMILO, 2014, p. 634).

No que tange aos Direitos Humanos da Criança e do Adolescente, vemos que além de gozarem de todos os direitos inerentes ao homem em sua sociedade, é garantido à criança e ao adolescente o princípio da prioridade, segundo o qual, proteção e satisfação devem ser asseguradas pelo Estado antes de quaisquer outros. Esse princípio está evidenciado em diversos documentos internacionais, como a Declaração dos Direitos da Criança, assinada em Genebra, em 1924; a Declaração Universal dos Direitos das Crianças, de 1959, e a Convenção das Nações Unidas sobre os Direitos da Criança, de 1989.

A partir da Assembléia das Nações Unidas de 20 de novembro de 1959, o Brasil adotou a Declaração dos Direitos da Criança e a ratificou através do art. 84, inciso XXI, da Constituição, tendo em vista o disposto nos artigos $1^{\circ}$ da Lei $n^{\circ} 91$, de 28 de agosto de 1935 e $1^{\circ}$ do Decreto $\mathrm{n}^{\mathrm{o}} 50.517$, de 2 de maio de 1961. Com o passar do tempo, esses documentos passaram por reformulações na área jurídica, a partir da movimentação social de setores das ciências e práticas sociais, culminando no Estatuto da Criança e do Adolescente, de 1990, e na Política Nacional dos Direitos Humanos de Crianças e Adolescentes, assim como no Plano Decenal dos Direitos Humanos de Crianças e Adolescentes (BRASIL, 2010).

Considerando a história dos Direitos Humanos, dos Direitos da Criança e de outros tratados que têm como base a eliminação de todo tipo de discriminação, destacamos alguns 
eventos internacionais importantes para a inclusão, pois foi a partir destes movimentos que teve início a construção de seus princípios. Em âmbito internacional destacamos os eventos: a Conferência Mundial de Educação para Todos, realizada em Jomtiem, na Tailândia, em 1990, e a Conferência Mundial sobre Necessidades Especiais: Acesso e Qualidade, promovida pelo governo da Espanha e pela UNESCO, em 1994.

Quanto ao direito de todos à educação, destacamos que foi reconhecido na Declaração de 1948 e fortalecido como norma jurídica internacional, principalmente, pelo Pacto Internacional dos Direitos Econômicos, Sociais e Culturais (artigos 13 e 14), da Convenção Relativa à Luta contra a Discriminação no Campo do Ensino, da Convenção sobre os Direitos da Criança (artigos 28 e 29) e do Protocolo Adicional à Convenção Americana sobre Direitos Humanos em Matéria de Direitos Humanos Econômicos, Sociais e Culturais (artigo 13).

\section{O surdo e a surdez}

O surdo é um sujeito portador de necessidades especiais, mas acima de qualquer singularidade, é um cidadão brasileiro e, como tal, tem seus direitos como cidadão comum. O artigo $5^{\circ}$ da Constituição da República Federativa do Brasil assevera que:

Todos são iguais perante a lei, sem distinção de qualquer natureza, garantindo-se aos brasileiros e aos estrangeiros residentes no País a inviolabilidade do direito à vida, à liberdade, à igualdade à segurança e à propriedade (BRASIL, 1988).

Além do que a Constituição garante a todo cidadão brasileiro, o surdo criança ou adolescente pode também contar com o Estatuto da Criança e do Adolescente e a Lei de Acessibilidade. O Artigo $1^{\circ}$ do Relatório das Convenções sobre os Direitos das Pessoas com Deficiência, de 2009, que também assegura direitos ao surdo, afirma a necessidade de "promover, proteger e assegurar o exercício pleno e equitativo de todos os Direitos Humanos e liberdades fundamentais por todas as pessoas com deficiência e promover o respeito pela sua dignidade inerente" (BRASIL, 2009).

Nesse documento, as pessoas com deficiência são descritas como "aquelas que têm impedimentos de longo prazo de natureza física, mental, intelectual ou sensorial, os quais, em interação com diversas barreiras, podem obstruir sua participação plena e efetiva na sociedade 
em igualdades de condições com as demais pessoas" (BRASIL, 2009). Como deficiência sensorial, temos a surdez. O Censo do IBGE (2010) aponta que o Brasil tem 4,6 milhões de pessoas com deficiência auditiva e 1,1 milhão são surdas, totalizando aproximadamente 5,7 milhões de pessoas.

Um ser humano é constituído por várias dimensões complexas, tais como: biológica, psicológica, social, cultural e a cognitiva. De acordo com Galvão et al (2013, p.196), são frequentes as situações em que, vulgarmente, pessoas com deficiência são reduzidas às dificuldades intrínsecas da deficiência, no caso do surdo, a audição, ou melhor, a falta dela. Partindo desse conceito, considera-se que a cultura surda é configurada a partir da percepção do surdo sobre o mundo, a fim de compreender suas mudanças ao ponto de torná-lo acessível e habitável. Strobel (2008b, p. 22) afirma que a cultura surda se compõe com as diversas percepções do sujeito, ou seja, "abrange a língua, as ideias, as crenças, os costumes e os hábitos de povo surdo".

O decreto de lei 5626, em seu Art. 2o, considera pessoa "surda aquela que, por ter perda auditiva, compreende e interage com o mundo por meio de experiências visuais, manifestando sua cultura principalmente pelo uso da Língua Brasileira de Sinais - Libras" (BRASIL, 2005). Destacamos no mesmo documento o Parágrafo único que considera a surdez a partir de uma visão médico-quantitativa, como uma "deficiência auditiva a perda bilateral, parcial ou total, de quarenta e um decibéis $(\mathrm{dB})$ ou mais, aferida por audiograma nas frequências de $500 \mathrm{~Hz}, 1.000 \mathrm{~Hz}, 2.000 \mathrm{~Hz}$ e $3.000 \mathrm{~Hz} "$ (BRASIL, 2005).

Os movimentos efetivados pelos surdos, em prol de sua língua e cultura, foram reforçados pelo reconhecimento da Lei 10.436 de 2002, que defende a inclusão da língua de sinais brasileira, a Libras, nos espaços sociais, favorecendo não só o sujeito surdo, como a todos os portadores de alguma deficiência, tornando-os assim visíveis à sociedade. Ao estudar as diferentes formas de comunicação, Sánchez ressalta a comunicação humana, afirmando-a como superior:

[...] a comunicação humana é essencialmente diferente e superior a toda outra forma de comunicação conhecida. Todos os seres humanos nascem com os mecanismos da linguagem específicos da espécie, e todos os desenvolvem naturalmente, independente de qualquer fator racial, social ou cultural (SÁNCHEZ, 1990, p. 17 apud QUADROS, 1997, p.45). 
O Governo do Estado de Goiás tem procurado adequar o Plano Estadual de EducaçãoPEE, 2008-2017, para cumprir as metas propostas pelo Plano Nacional de Educação PNE. O documento, que apresenta a Avaliação do Plano Estadual de Educação 2008 - 2017, analisa criticamente as metas e objetivos desse Plano, a partir de estudos realizados pela comissão estabelecida da Secretaria Regional de Educação (SRE), por meio de seu Departamento Pedagógico, com a participação da sociedade e da comunidade escolar pública. De acordo com o documento, o amplo debate entre as partes envolvidas,

[...] estendeu-se ao âmbito municipal, por meio da realização de nove (9) plenárias e calcou o cume com a realização da Audiência Pública na qual as contribuições apresentadas foram avaliadas pelos representantes das entidades participantes. Para compor os textos-bases preliminares à discussão, foi utilizado como referência o Plano Nacional de Educação e o Plano Estadual Educação. As prioridades que se seguem são respaldadas nos diagnósticos consolidados, aqui apresentados, produzidos pelo coletivo que discutiram as bases deste Plano. Os resultados tangíveis de medidas concentradas no ataque dos problemas prioritários vinculam-se, necessariamente, a conjuntos de ações programáticas que, de modo direto ou mediato, envolvem vários segmentos do poder público e representações civis (GOIÁS, 2008).

Destacamos algumas das metas que visam a Educação Especial, mais especificamente, aquelas nas quais o surdo é contemplado. Essas metas se subdividem quanto à mobilidade no ensino básico, superior e na formação de professores. Na formação superior, destacamos a Meta 4, que propõe, nas Universidades e IES, a ampliação de: "habilitação específica, em nível de graduação e de pós-graduação, para formar pessoal especializado em educação especial" (GOIÁS, 2008, p. 60) e a meta 6, que recomenda a inclusão de conhecimentos sobre educação infantil, educação especial e educação de jovens e adultos nos cursos de formação de professores. Na formação básica do discente, a meta 4 é universalizar o acesso à rede regular de ensino, com garantia de um sistema educacional inclusivo tanto na rede publica quanto conveniados. Além das metas, o PEE (GOIÁS, 2008), no que diz respeito à inclusão, também sugere:

1) Incentivar a inclusão de disciplinas nos cursos de licenciatura e criar cursos de pós-graduação mantidos pelo poder público relacionado ao ensinoaprendizagem e ao atendimento educacional aos alunos com necessidades especiais. 
2) Fomentar a educação inclusiva por meio de articulação dos centros multidisciplinares de apoio com profissionais de diversas áreas, para apoiar o trabalho dos professores da educação básica com os alunos com necessidades educacionais especiais.

3) Apoiar e ampliar as equipes de profissionais da educação para atender os estudantes com deficiência, garantindo a oferta de professores do atendimento educacional especializado, de profissionais de apoio ou auxiliares, tradutores e intérpretes de LIBRAS, guias-intérpretes para surdocegos, professores de LIBRAS, prioritariamente surdos e professores bilíngues.

4) Incentivar e garantir financiamento de pesquisas científicas sobre gênero, orientação sexual e identidade de gênero, relações étnico-raciais e antirracistas, educação ambiental, educação quilombola, indígena, dos povos do campo, dos povos da floresta, dos povos das águas, ciganos, educação das pessoas com deficiência, pessoas jovens, adultas e idosas em situação de privação de liberdade e diversidade religiosa (GOIÁS, 2008).

Esses trechos do PEE ilustram como a diversidade de leis, planos, decretos, censos e metas foi resultado da inquietação e da luta da comunidade surda em prol da sua língua, cultura, educação e acessibilidade. Acima de tudo, pelo acolhimento pleno por parte do país do qual o surdo é cidadão. São ações concretas que contribuem para que a sociedade, majoritariamente ouvinte, possa compreender melhor as singularidades do surdo e da surdez,

\section{Metodologia}

Pesquisa qualitativa com aplicação de entrevistas semiestruturadas com profissionais que lidam diretamente com o surdo na escola. De acordo com Minayo (2010, p. 57), o método qualitativo pode ser definido como:

[...] o que se aplica ao estudo da história, das relações, das representações, das crenças, das percepções e das opiniões, produtos das interpretações que os humanos fazem a respeito de como vivem, constroem seus artefatos e a si mesmos, sentem e pensam. Embora já tenham sido usadas para estudos de aglomerados de grandes dimensões (IBGE, 1976; Parga Nina et.al 1985), as abordagens qualitativas se conformam melhor a investigações de grupos e segmentos delimitados e focalizados, de histórias sociais sob a ótica dos atores, de relações e para análises de discursos e de documentos.

A amostra é constituída por entrevista de gestores/intérpretes de duas escolas públicas do município de Goiânia. Participaram da entrevista uma Intérprete, uma coordenadora do 
Atendimento Educacional Especializado e uma fonoaudióloga da Equipe multiprofissional do da Secretária Estadual de Educação (SEE).

Os critérios de seleção das escolas foram: ter alunos surdos matriculados, ter disponibilidade de tempo para a entrevista e assinar o Termo de Consentimento Livre e Esclarecido (TCLE) autorizando a gravação da voz. Trata-se de um trabalho de campo, com o objetivo de suscitar questionamentos sobre a inclusão do surdo. Para realização deste estudo, foi necessário um levantamento das leis e decretos que protegem e dão a garantia de direitos aos surdos (Lei no 12.081/1993, n ${ }^{0} 10.098 / 2000$, Art. 18; Lei $n^{\circ} 10.436 / 2002$; Decreto $n^{\circ}$ 5.626/2005 e Decreto ${ }^{\circ}$ 7.611/2011) livros, artigos e dissertações.

O método utilizado foi o da entrevista semiestruturada, elaborada previamente pelo pesquisador. As entrevistas foram gravadas e, em seguida, transcritas. Elegemos para o tratamento dos dados a Análise de Conteúdo, com a técnica de Analise Temática. As categorias foram organizadas de forma não apriorística, a partir de dois descritores, sendo eles: (Co) responsabilização e Lócus. De acordo com Campos (2004), a categorização não apriorística emerge do contexto das respostas dos sujeitos da pesquisa, o que inicialmente exige do pesquisador um intenso ir e vir ao material analisado e a consulta a teorias fundantes, além de não perder de vista o atendimento aos objetivos da pesquisa.

Também foi utilizada a fenomenologia, com o objetivo de buscar a essência da realidade pesquisada. Lalande (1999, p. 397) define de forma geral a fenomenologia como um "estudo descritivo de um conjunto de fenômenos, tal como eles se manifestam no tempo ou no espaço, por oposição quer às leis abstratas e fixas destes fenômenos, quer à realidade transcendente de que seria a manifestação, quer à crítica normativa da sua legitimidade". Rezende (1990, p.46) considera a educação um fenômeno que deve ser reconhecido como uma experiência profundamente humana, ressaltando que todos os homens se educam e só eles o fazem.

\section{Análise dos dados}

A educação, a inclusão do sujeito surdo, é um direito humano. Ao tratar a educação

como um direito humano, destacamos que, independe das condições econômicas dos estudantes, pois esta não se limita à condição social, nacional, cultural, de gênero ou étnico- 
racial da pessoa. O mais importante é conseguir que todas as pessoas possam estar conscientes de seus direitos e exercê-los. Nesse sentido, o tópico 2 do artigo 26 da Declaração Universal de 1948 é fundamental na definição dos propósitos universais da educação.

As diversas leis criadas no país, cada uma com um propósito e utilização, convergem para a busca de uma melhor qualidade de vida do surdo, independente do lócus. Foi pensando na convergência dessas leis que destacamos dois pontos, a partir das categorias de análise e das entrevistas para discutirmos sobre a realidade enfrentada pelos educandos surdos nas escolas.

\begin{tabular}{|c|l|l|}
\hline CATEGORIAS & \multicolumn{1}{c|}{ TRECHOS DAS ENTREVISTAS } \\
\hline DE ANÁLISE & $\begin{array}{l}\text { "O ano passado eu estava com ele aqui nessa escola, na } 5^{a} \text { serie (ano). Só que eu pedi } \\
\text { para a mãe, conversei com a diretora, com o coordenador pedagógico, conversei com } \\
\text { quem era de direito, né?! Eu falei que não convinha passar ele para o } 6^{a} \text { ano. Tinha } \\
\text { nota? Tinha, porque a professora foi dando nota para ele." } \\
\text { (Co)responsáveis eu corrijo na frente dele, falo que está errado, ele apaga e faz de novo." } \\
\text { "Eu não mando tarefa para casa, porque eu acho que ele não tem acompanhamento } \\
\text { em casa. Então o acompanhamento dele é comigo." } \\
\text { "O professor tem que saber que ele é o professor do aluno e que esse processo de } \\
\text { comunicação, essa relação Professor-Aluno não pode ter um intérprete no meio. E o } \\
\text { fato de você não saber a língua do outro que você esta impossibilitado de tentar se } \\
\text { comunicar, porque há outros recursos na comunicação." } \\
\text { "Nós tivemos surdos que vieram de outra escola que a interprete copiava a matéria } \\
\text { para ela. Isso é papel do intérprete? Não! A aluna não tinha problema algum motor." } \\
\text { "Seu aluno é surdo, custa aprender o sinal dele? É uma questão de } \\
\text { respeito/acolhimento para com o outro na sua diferença, somos na verdade todos } \\
\text { diferentes, igualdade não existe, então aprenda o sinal do seu aluno." } \\
\text { "O nível dele é baixo, mas isso é papel do intérprete? Não, não é. Mas eu me sinto, } \\
\text { sabe? Eu me sinto bem fazendo isso." } \\
\text { "Porque assim, não tem sentido eu ficar na frente dele traduzindo o que a professora } \\
\text { esta falando e ele voando." } \\
\text { "Eu sei que isso função minha. Eu tenho plena consciência disso, mas eu não posso } \\
\text { fechar os olhos para uma criança que esta pedindo socorro." }\end{array}$ \\
\hline
\end{tabular}




\begin{tabular}{|c|c|}
\hline Lócus & $\begin{array}{l}\text { "Sim, sou a única pessoa que sabe LIBRAS da escola, ou se sabem é só o basiquinho, } \\
\text { mesmo." } \\
\text { "Aqui como uma escola de tempo integral, acho que ele não pode sair. Assim, não } \\
\text { pode sair... ou aqui deveria ter o AEE." } \\
\text { "Nós temos aqui na escola com relação aos alunos percebido uma pequena mudança, } \\
\text { quanto ao respeito as diferenças..." } \\
\text { "O ano passado eu estava com ele aqui nessa escola, na } 5^{\text {a }} \text { série (ano). Só que eu pedi } \\
\text { para a mãe, conversei com a diretora, com o coordenador pedagógico, conversei com } \\
\text { era de direito, né?! Eu falei que não convinha passar ele para o } 6^{\mathrm{a}} \text { ano. Tinha nota? } \\
\text { Tinha, porque a professora foi dando nota para ele." }\end{array}$ \\
\hline
\end{tabular}

A categoria dos (co) responsáveis destaca os papéis e as ações desempenhadas pelos profissionais que lidam com o sujeito surdo. A partir dos trechos citados nessa categoria, identificamos a transferência de papéis, a responsabilização do profissional intérprete na educação do surdo e este profissional tomando decisões que extrapolam sua função. A legislação e o código de ética da profissão delimitam as responsabilidades por parte do intérprete, vistas a partir dos trechos destacados no quadro acima.

De acordo com Quadros (2004, p. 29), o professor tem o papel fundamental, associado ao ensino e, portanto, completamente inserido no processo interativo social, cultural e lingüístico. $\mathrm{O}$ intérprete, por outro lado, é o mediador entre pessoas que não dominam a mesma língua, abstendo-se, na medida do possível, de interferir no processo comunicativo. A mesma autora salienta que "cada profissional desempenha sua função e papel que se diferenciam imensamente". O professor de surdos "deve" saber e utilizar muito bem a língua de sinais, mas isso não implica ser intérprete de língua de sinais ou a dispensa desse profissional.

Fator importante sobre o primeiro ponto é a outorga de papéis, pois há professores que passam para o profissional intérprete um papel para além da sua responsabilidade. Chegam a não perceber, não acolher o educando surdo. Rezende (1990 p. 48) afirma que a não percepção do sujeito e de suas dimensões elimina radicalmente alguns de seus aspectos importantes.

O corpo do homem não é um simples corpo, mas corpo humano, que só pode ser compreendido a partir de sua integração na estrutura global, ou seja, no contexto no qual está inserido. Para a fenomenologia, ao falar de 
aprendizagem humana, quer dizer que se trata, de aprender de maneira humana a sermos homens para existirmos como tais. É o que se torna ainda mais claro que esta deve ser também uma aprendizagem significativa. (REZENDE, 1990, p. 48).

Quanto a categoria Lócus, relaciona-se a apontar ações a serem desenvolvidas em prol do educando. Para Dorziat (1998) o aperfeiçoamento da escola comum em favor de todos os alunos é fundamental. Essa autora observa que os professores precisam conhecer e usar a Língua de Sinais, entretanto, deve-se considerar que a simples adoção dessa língua não é suficiente para escolarizar o aluno com surdez. Assim, a escola comum precisa implementar ações que tenham sentido para os alunos em geral e que esse sentido possa ser compartilhado pelos alunos com surdez. Mais do que a utilização de uma língua, os alunos surdos precisam de ambientes educacionais estimuladores, que desafiem o pensamento e explorem suas capacidades, em todos os sentidos.

\section{Considerações finais}

O meio em que o sujeito surdo está inserido, principalmente a escola, deve permitir e proporcionar trocas que sejam significativas, pois o educando com surdez, segundo Poker (2002), precisa ser estimulado física, social e cognitivamente, se isso não acontecer, terá seu desenvolvimento intelectual comprometido. Corroborando esse pensamento, Damazio (2007) salienta que há inúmeras polêmicas em torno da educação escolar para pessoas com surdez.

A proposta de educação escolar inclusiva é um desafio. Para ser efetivada, faz-se necessário considerar que os alunos surdos têm direito de acesso ao conhecimento, à acessibilidade, bem como ao Atendimento Educacional Especializado. Conforme Bueno (1999, p. 41), é preciso ultrapassar a visão que reduz os problemas de escolarização das pessoas com surdez ao uso desta ou daquela língua, mas ampliar a discussão para os diversos campos que discutem e defendem a causa surda.

Há falhas na inclusão do educando surdo no que diz a respeito à sua plena participação no sistema de ensino, na sua relação com a comunidade educacional, na delimitação da função do intérprete, à falta de qualificação do professor para lidar com o educando surdo, à estrutura das instituições que lidam com o educando e nas instituições que acolhem este discente. Para além destes pontos, no que tange aos Direitos Humanos, quanto à 
acessibilidade, igualdade de oportunidades há vários pontos que ainda precisam ser revistos e percebidos para que haja o efetivo cumprimento dos direitos destes educandos e uma aprendizagem significativa.

\begin{abstract}
The education of the deaf is a hot topic and has been much explored in recent years, both in isolation and in the interdisciplinarity of areas such as education and human rights. This article aims to reveal, from the speech of professionals who deal directly with the deaf subject in the school environment, how the inclusion of this subject is occurring, with a view to inclusion for the promotion of Human Rights. Transversal research with qualitative design was done by conducting semi-structured interviews with managers and Libras interpreters of two public schools in the city of Goiânia. It is concluded that there are efforts by the legal, institutional and professional part for an effective inclusion of the deaf students, but these still present difficulties resulting in a faulty reception regarding human dignity. The results of this research show that the inclusion of the deaf student is happening only at social level and not at the cognitive level, which should not be, because to include is to provide conditions for the access, permanence and graduation of the school learner.
\end{abstract}

Keywords: Human Rights, Inclusion, Deaf.

\title{
Resumen
}

La educación del sordo es un tema de moda y se ha investigado mucho en los últimos años, tanto de forma aislada, como en campos interdisciplinarios, tales como la Educación y los Derechos Humanos. Este artículo tiene el objetivo de evaluar, desde el punto de vista de profesionales que trabajan directamente con sordos en el ambiente escolar, como está ocurriendo la inclusión de ese individuo, observando la inclusión para la promoción de los Derechos Humanos. Se usó una investigación transversal-cualitativa, con aplicación de entrevistas semi-estructuradas con los administradores e intérpretes de Libras de dos escuelas públicas de la ciudad de Goiânia. Se concluyó que existen esfuerzos legislativos, institucionales y profesionales para la efectiva inclusión del individuo sordo, pero éstos todavía relatan dificultades relacionadas al acogimiento, ya que se considera insuficiente en lo relacionado a dignidad humana. Los resultados de esta investigación demuestran que la inclusión del educando sordo está ocurriendo solamente a nivel social y, no a nivel cognitivo, hecho que no debería acontecer, pues, incluir es proporcionar condiciones para el acceso, la permanencia y la salida del educando de la escuela.

Palabras-clave: Derechos Humanos, Inclusión, Sordo. 


\section{Referências}

BRASIL. Constituição da República Federativa do Brasil: promulgada em 5 de outubro de 1988. São Paulo: Saraiva, 1988.

. Lei n ${ }^{\circ} 10.436$, de 24 de abril de 2002. Dispõe sobre a Língua Brasileira de Sinais Libras e dá outras providências. Diário Oficial [da] União, Brasília, DF, 25 abr. 2002. Disponível em: http://www.planalto.gov.br/ccivil_03/leis/2002/L10436.htm. Acesso em: 10 jun. 2017.

Decreto $n^{\circ}$ 5.626, de 22 de dezembro de 2005. Regulamenta a Lei $n^{\circ} 10.436$, de 24 de abril de 2002, que dispõe sobre a Língua Brasileira de Sinais - Libras. Diário Oficial [da] União, Brasília, DF, 23 dez. 2005.

Disponível em: http://www.planalto.gov.br/ccivil_03/_ato20042006/2005/decreto /d5626.htm Acesso em: 10 jun. 2017.

Construindo a Política Nacional dos Direitos Humanos de Crianças e Adolescentes e o Plano Decenal dos Direitos Humanos de Crianças e Adolescentes 20112020. Conselho Nacional dos Direitos da Criança e do Adolescente. Brasília, 2010. Disponível em:

https://www.unicef.org/brazil/pt/PoliticaPlanoDecenal_ConsultaPublica.pdf. Acesso em: 8 jun. 2017.

. Decreto $\mathrm{n}^{\circ}$ 6.949, de 25 de agosto de 2009. Promulga a Convenção Internacional sobre os Direitos das Pessoas com Deficiência e seu Protocolo Facultativo, assinados em Nova York, em 30 de março de 2007. Diário Oficial [da] União, Brasília, DF, 25 ago. 2009. Disponível em: http://www.planalto.gov.br/ccivil_03/_ato2007-2010/2009/decreto/d6949.htm Acesso em: 10 jun.2017.

BUENO, José Geraldo Silveira. "Diversidade, deficiência e educação". In: Revista Espaço. Rio de Janeiro: INES. n 12, p. 3-12, julho-dezembro, 1999.

CAMILO, Christiane de Holanda. Direitos Humanos e Relações Étnico-Raciais na Rede Municipal de Educação de Goiânia - Goiás. 27/02/2014. 215f. Dissertação [Mestrado em Direitos Humanos] Universidade Federal de Goiás - UFG, Goiânia, 2014.

CAMPOS, Claudinei José Gomes. Método de análise de conteúdo: ferramenta para a análise de dados qualitativos no campo da saúde. In: RevBras Enfermagem, Brasília (DF) 2004 set/out;57(5):611-4

CUNHA, A. G. Dicionário Etimológico Nova Fronteira da Língua Portuguesa. 2.ed. Rio de Janeiro: Nova Fronteira, 2000.

DAMÁZIO, Mirlene Ferreira Macedo. Formação Continuada a Distância de Professores para o Atendimento Educacional Especializado Pessoa com Surdez. SEESP / SEED / MEC.Brasília/DF - 2007. 
UNESCO. Declaração Universal dos Direitos Humanos: adotada e proclamada pela Assembléia Geral das Nações Unidas (resolução 217 A III) em 10 de dezembro 1948. Disponível em: http://www.onu.org.br/img/2014/09/DUDH.pdf . Acesso em: 1 de jun. 2017.

DORZIAT, Ana. Democracia na escola: bases para igualdade de condições surdos-ouvintes. In: Revista Espaço. Rio de Janeiro: INES. nº 9, p. 24 -29, janeiro-junho,1998.

FUZIWARA, Aurea Satomi. Lutas Sociais e Direitos Humanos da criança e do adolescente: uma necessária articulação. Serviço Social \& Sociedade, São Paulo, n. 115, Set. 2013.

GALVAO, M. V. A.; NASCIMENTO, S. R. ; DUARTE, S. B. R. . O escolar surdo e suas dimensões constitutivas: a escuta musicoterapêutica como integração. XXI SIMPÓSIO DE ESTUDOS E PESQUISAS DA FACULDADE DE EDUCAÇÃO DA UNIVERSIDADE FEDERAL DE GOIÁS - Pedagogia e Psicologia: formação e identidade social, Goiânia. Anais, 2013. P. 196-211

GOIÁS. Comissão Estadual de Avaliação: adequação do Plano Estadual de Educação 2008/2017. Secretaria de Estado de Educação, Cultura e Esporte. Plano Estadual de Educação - 2008-2017. Lei Complementar $n^{\circ}$ 62, de 9 de out. 2008, Diário Oficial do Estado de Goiás, de 17 out. 2008.

Disponível em: http://www.seduc.go.gov.br/pee/PlanoEducacaoVisualizacao.aspx. Acesso em: 22 jun. 2017.

IBGE, Instituto Brasileiro de Geografia e Estatística. Censo demográfico Brasileiro, 2010. Diponível em: http://www.ibge.gov.br/home/estatistica/populacao/censo2010/default.shtm . Acesso em: 12 jun. 2017.

LALANDE, A. Vocabulário técnico e crítico da Filosofia. Trad. Fátima Sá Correia et al. $3^{\text {a }}$ ed. São Paulo: Martins Fontes, 1999.

MINAYO, M.C. de S. O desafio do conhecimento: Pesquisa Qualitativa em Saúde. 12a edição. São Paulo: Hucitec-Abrasco, 2010.

PAULA, Heloisa Vitoria de Castro de; PAULA, Maristela Vicente de. Direitos Humanos da Criança e Adolescente: um olhar histórico-social. In: AVA UFG- Catalão, 2015. Disponivel em: http://ead.catalao.ufg.br/mod/resource/view.php?id=12378 . Acesso em: 13 jul. 2016.

POKER, R. B. Troca simbólica e desenvolvimento cognitivo em crianças surdas: uma proposta de intervenção educacional. Tese de doutorado. UNESP - Marília, 2002.

QUADROS, Ronice Muller. A Educação de surdos: a aquisição da linguagem. Porto Alegre: Artmed, 1997.

O tradutor e intérprete de língua brasileira de sinais e língua portuguesa

/ Secretaria de Educação Especial; Programa Nacional de Apoio à Educação de Surdos Brasília : MEC ; SEESP, 2004. 
RESENDE, Antônio Muniz de. Concepção fenomenologia da Educação. São Paulo: Cortez: autores Associados, 1990.

Karin Lilian. Surdos: Vestígios Culturais não Registrados na História. Tese de Doutorado em Educação - UFSC - Universidade Federal de Santa Catarina. Florianópolis, 2008.

TRINDADE, J. D. L.. História social dos Direitos Humanos. São Paulo: Petrópolis, 2003. 